\title{
A Novel Mutation in the BCKDHB Gene Causes in an Iranian Child Classic Maple Syrup Urine Disease
}

\author{
Esmat Safdarian, ${ }^{1}$ Hamid Galehdari, ${ }^{2,}$ Vahab Jafarian,, Mohammad Shafee, ${ }^{2}$ Gholamreza Shariati, ${ }^{3}$ \\ Mohammad Hamid, ${ }^{3}$ and Alihossein Saberi ${ }^{3}$ \\ ${ }^{1}$ Department of Biology, Faculty of Sciences, University of Zanjan, Zanajn, IR Iran \\ ${ }^{2}$ Department of Genetics, Faculty of Sciences, Shahid Chamran University of Ahvaz, IR Iran \\ ${ }^{3}$ Narges Genetics Laboratory, Ahvaz, IR Iran \\ "Corresponding author: Hamid Galehdari, Department of Genetics, Faculty of Sciences, Shahid Chamran University of Ahvaz, IR Iran. E-mail: galehdari187@yahoo.com
}

Received 2015 July 05; Revised 2015 August 15; Accepted 2016 September 24.

\begin{abstract}
Background: Maple syrup urine disease (MSUD) is a rare metabolic disorder caused by deficiency in branched chain alpha-keto acid dehydrogenase complex (BCKD).

Methods: In this study, the coding regions and flanking splice sites of the BCKDHA, BCKDHB, DBT and DLD genes have been sequenced in an Iranian 3 years old girl.

Results: A novel homozygous mutation (p.Glu330Lys) was detected in the BCKDHB gene. In silico analysis showed significant change in the 3-D protein Structure.

Conclusions: This alteration probably affects the structure and function of the E1 $\beta$ subunit of BCKD complex.

Keywords: Maple Syrup Urine Disease, Inborn Metabolic Disorder, Amino Acid Metabolism
\end{abstract}

\section{Introduction}

Maple syrup urine disease (MSUD; OMIM ID \# 248600) is an autosomal recessively inherited error of metabolism resulting from the deficiency in the mitochondrial branched-chain alpha keto acid dehydrogenase complex caused by mutations in one of the four genes BCKDHA, $\mathrm{BCKDHB}, \mathrm{DBT}$ and DLD. There are at least five main clinical phenotypes in MSUD patients differing in presentation and severity of the disease. The majority of affected individuals $(\sim 75 \%)$ have the classic form of the disease in which the residual enzymatic activity is near $2 \%$ of normal activity [1-6].

The estimated worldwide incidence of MSUD ranges from 1 in 185,000 to 1 in 940,000 in western countries; the prevalence is much higher in certain ethnic groups, specifically the Mennonite populations of Pennsylvania and other nearby states ( 1 in 176) [7].

We report here a novel homozygote missense mutation in the BCKDHB gene in the province Khuzestan.

\section{Methods}

\subsection{Patient}

The patient was a three years old girl, one of two children of consanguineous parent. The patient exhibited the classical clinical phenotype of MSUD. The medical diagnosis could only be completed later by the plasma amino acid analysis high BCAAs have been observed, with leucine at $1970 \mu \mathrm{mol} / \mathrm{L}$ (normal range $55-167 \mu \mathrm{mol} / \mathrm{L}$ ), isoleucine at $1978 \mu \mathrm{mol} / \mathrm{L}$ (normal range 52-283 $\mu \mathrm{mol} / \mathrm{L}$ ). After obtaining an informed consent, all family members were questioned about their personal medical history.

\subsection{Sample Collection, DNA Isolation and Polymerase Chain Re- action}

Peripheral blood was collected from patient and her parents in the EDTA tubes. The DNA was extracted by the standard salting out protocol, and the quality of the extracted DNA was verified by gel electrophoresis. All coding exons of the BCKDHA, BCKDHB, DBT and DLD genes were amplified by PCR using primers designed by software Primer3 (http://primer3.ut.ee/). Primers are showed in Table 1.

The PCR was performed in the following conditions: 100 ng genomic DNA, $200 \mu \mathrm{M} \mathrm{dNTP,} 1.5 \mathrm{mM} \mathrm{MgCl}_{2}, 2.5$ units 
Table 1. Sequences of the Forward and Reverse Primers Used for Separate Amplification of Exons in the BCKDHB Gene

\begin{tabular}{|c|c|c|c|c|}
\hline Exon & Forward Primer & Reverse Primer & Amplicon Length, bp & $\mathrm{Tm},{ }^{\circ} \mathrm{C}$ \\
\hline $\mathbf{1}$ & 5'-GCCACCTCTAGCCCACACTTCC-3' & 5'-AATAAGCTGGGATGCAAGGA-3' & 438 & 59.6 \\
\hline 2 & 5'-TGTATTTTACAACACACGAAATGA-3' & 5'-TGTTAACCATTGAGCTCCACA-3' & 216 & 59.0 \\
\hline 3 & 5'TGCACTGTTGGCTTGCGAGACAA-3' & 5'-TTCTGCGGGTGGCGTTGGAA-3' & 170 & 60.1 \\
\hline 4 & 5'-CCTTGATCGAGATCTATGGTCC-3' & 5'-TCCATACAATGGGGATATGACA-3' & 307 & 60.3 \\
\hline 5 & 5'-TACCACCATCCATCACCAGA-3' & 5'-TGAATAAGGCAGTCACAAAAGG-3' & 192 & 61.2 \\
\hline 6 & 5'-CATGACATTACTCTCATTTGCCA-3' & 5'-GGGTAGCGGCAATACTTGAA-3' & 250 & 59.6 \\
\hline 7 & 5'TGCACAAGTGTCACCTCAGA-3' & 5'-GCTTCCAAGCACAACGTAGG-3' & 205 & 59.7 \\
\hline 8 & 5'-CCACATGAATTGATTGTGAGC-3' & 5'-CAAAAATAACTTGCCTCGCA-3' & 176 & 59.4 \\
\hline 9 & 5'-ACCTGTCGAAAGCGAGTTGT-3' & 5'-GGAATTGCACAAGCATTGAA-3' & 294 & 59.7 \\
\hline 10 & 5'-GGATCATGCGAACATGCTGTTACC-3' & 5'-ACACTGATGATTGCTGTGTCTTGG-3' & 402 & 60.3 \\
\hline 11 & 5'-GCATTCAACTAGTTTTTGAGGC-3' & 5'-GCCAAAGGTTTCAGGGAAAT-3' & 226 & 59.5 \\
\hline
\end{tabular}

Super Taq polymerase, and 25 pmoL of each primer. Amplification was carried out in a total volume of $25 \mu \mathrm{L}$. After an initial denaturation at $93^{\circ} \mathrm{C}$ for 5 minutes, followed by 35 cycles of $93^{\circ} \mathrm{C}$ for 1 minute, annealing at $60^{\circ} \mathrm{C}$ for 30 seconds, and extension at $72^{\circ} \mathrm{C}$ for 45 seconds, and ended by a final extension at $72^{\circ} \mathrm{C}$ for 3 minutes.

PCR products were directly sequenced and analyzed by the ABI Prism 3700 automated genetic analyzer (Applied Biosystems). The results were analyzed and provide with Chromas, Fast-PCR, and compared with the reported gene sequence using the BLASTN program.

\section{Results}

Exons and the flanking intron sequences were amplified for each four genes. Figure 1 demonstrated PCR products for exons of the subjected genes.

Direct sequencing analysis of the patient and her parents after comparison with the NCBI reference sequence of the BCKDHA, the BCKDHB, the DBT, and the DLD genes demonstrated a homozygous missense mutation GAG $\rightarrow$ AAG substitution in the BCKDHB gene at exon 9, which causes an amino acid exchange of glutamate to lysine at codon 330 (Figure 2). This mutation has not been previously reported. Samples from parent showed the mentioned change in a heterozygous manner. We further evaluate the pathogenic properties of the mentioned change by different mutation prediction programs, which predicted it as pathogenic. DNA samples from 50 individuals were tested in order to confirm the absence of new identified mutation. The prediction of the functional effect of the missense single nucleotide alteration was done using software PolyPhen2 (Polymorphism Phenotyping v2) [8], SIFT
(Sorting Intolerant From Tolerant) [9], Mutation taster [10], and Predict SNP $[11,12]$. Results are summarized in the Table 2.

In addition, bioinformatics analysis by Swiss modeling software (www.swiss-prot.org) reveals that the mutant amino acid causes conformational changes in the sequence of BCKDHB gene. As visible in Figure 3, it changes the $\beta$-sheet conformation at first and totally effects whole protein structure.

\section{Discussion}

As described, a homozygous variant was identified in the BCKDHB gene in the affected girl. It was a missense mutation $\mathrm{G}>\mathrm{A}(\mathrm{E} 330 \mathrm{k}-\beta)$ located in exon 9 (c.1110G $>\mathrm{A})$ leading to an amino acid substitution of glutamate for lysine at position 330. Her parents were heterozygous for this mutation. Afterwards, for verifying the Pathogenicity of this mutation, PCR and direct sequencing was performed for exon 9 and its flanking regions in 50 unrelated individuals. Neither mutation was found in the 100 alleles of 50 normal individuals that were in the same ethnicity as the patient's family from Southwest Iran.

To date and regarding Human Genome Database (www.HGMD.org), more than 187 mutations have been found in the four MSUD causing genes BCKDHA, BCKDHB, DBT, and recently identified DTT gene responsible for mild form of MSUD. But, most reported mutations occur in the BCKDHA or the BCKDHB gene with 45 and 35 percents in MSUD patients worldwide, respectively (Genetics Home Reference, ww.ncbi.nlm.nih.gov).

According recent report, it seems that occurrence of some mutations in the MSUD causing genes depends on 


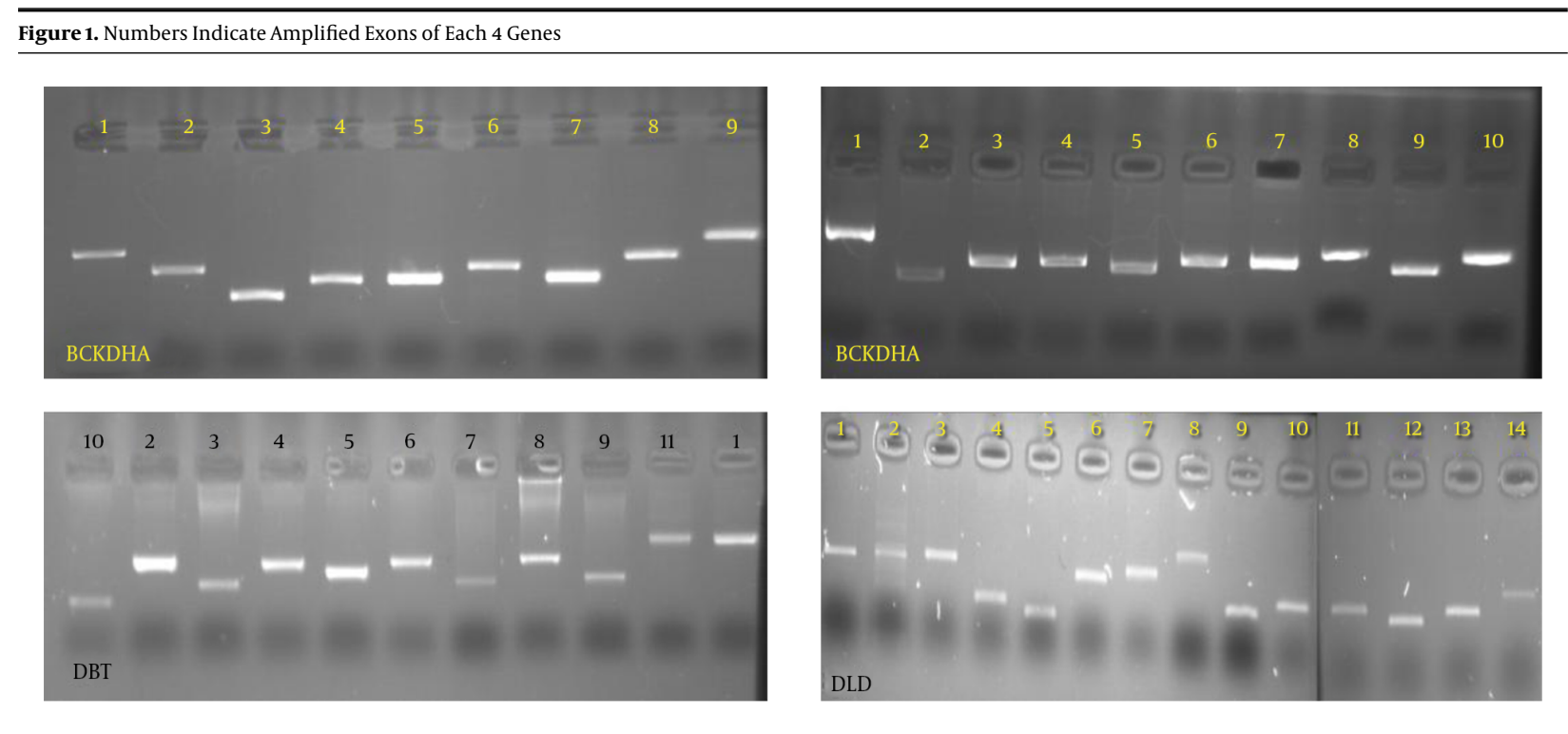

Upper-left BCKDHA gene, upper right BCKDHB gene, lower left DBT gene, and lower right DLD gene.
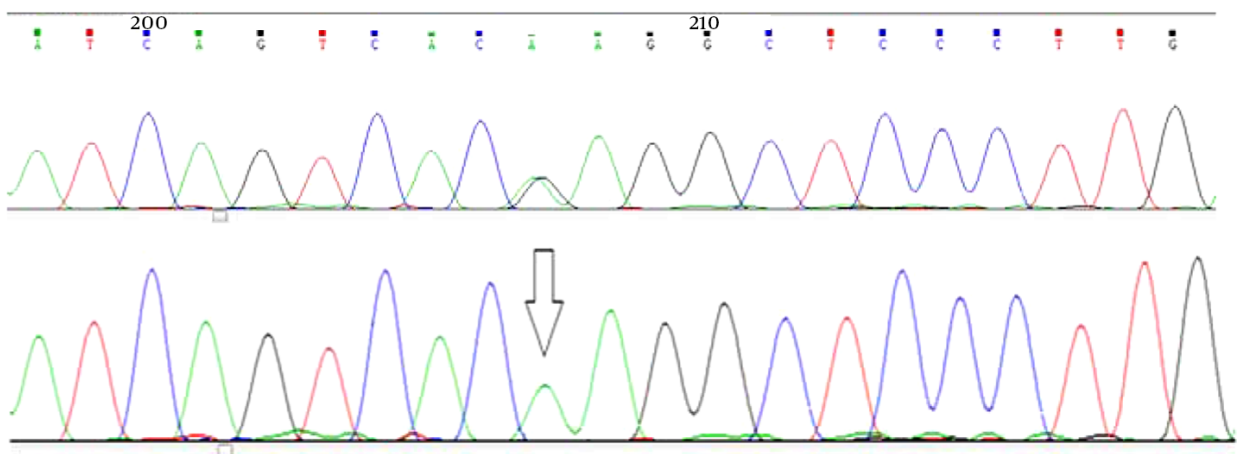

A) SEQUENCING

DIAGRAMS

$\begin{array}{rrrrrccccc}\text { ATC } & \text { AGT } & \text { CAC } & \text { AAG } & \text { GCT } & \text { CCC } & \text { TTG } & \text { B) MUTANT } & & \\ 327 & & 328 & & 329 & & 330 & 331 & 332 & 333 \\ & & & & & & & & & \\ \text { ATC } & \text { AGT } & \text { CAC } & \text { GAG } & \text { GCT } & \text { CCC } & \text { TTG } & \text { C) WILDTYPE } & & \\ 327 & & 328 & & 329 & & 330 & 331 & 332 & 333\end{array}$

Figure 2. Detected Homozygous Missense Mutation in Exon 9 of the BCKDHB Gene is Shown in A, Chromogram of Patient (Lower) Compared to Heterozygous Parents (Upper) Revealing E330K Amino Acid Change; B, in Comparison, Partial Mutant Sequence is Aligned Against A, Wild Type

ethnicities, so that targeted mutations could be suggested for individuals of certain geographic locations [13].

Divers mutation prediction programs suggested the novel change as pathogen (Table 2 ) with max score indexing. That means the highest probability for Pathogenicity. Furthermore, 3D structure protein model was created. Hereby, mutant versus wild type model was compared. As in the figure 2 has been showed, the conformation change might negatively affects the complex building between the $\mathrm{BCKDH}$ and its partners.

Considering the above mentioned findings, and clinical evidence of MSUD diagnosis in the patient we conclude that the nucleotide change is causative for the outbreak of disease and will extend the mutation list of MDUD patients. This is significant for screening of affected individuals at least in southwest Iran. Despite, functional study 
Table 2. Diverse Prediction Programs Have Been Used for Improving Pathogenic Nature of the Novel Change in the BCKDHB Gene. The Last Two Columns Show the Scoring of Benign Versus Damaging Prediction. According Mentioned Prediction Programs, the Novel Mutation is Pathogen With High Probability

\begin{tabular}{|c|c|c|c|c|}
\hline Program & Result & Score of Detected Change in This Report & Benign Score & Damaging Score \\
\hline Sift & Damaging & 0.0 & 1.0 & 0.0 \\
\hline Polyphen2 & Damaging & 1.0 & 0.0 & 1.0 \\
\hline Mutation Taster & Pathogen & $>0.5$ & $<0.5$ & Close to 1 \\
\hline Snap & Non-Natural & $85 \%$ & $<50 \%$ & $100 \%$ \\
\hline Mutation Assessor & pathogen & $92 \%$ & $<50 \%$ & $100 \%$ \\
\hline
\end{tabular}

Figure 3. Comparison of Wild Type and Mutant Protein Structures

A

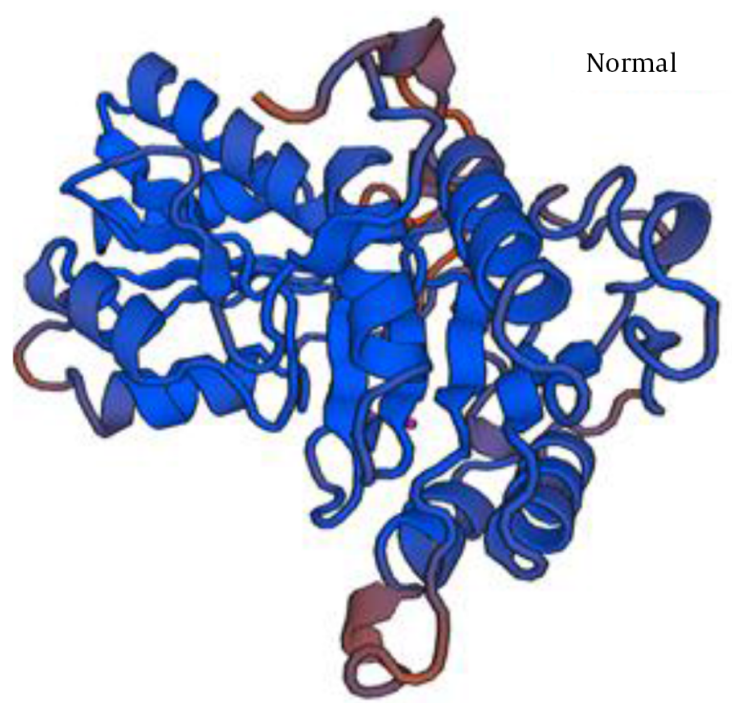

B

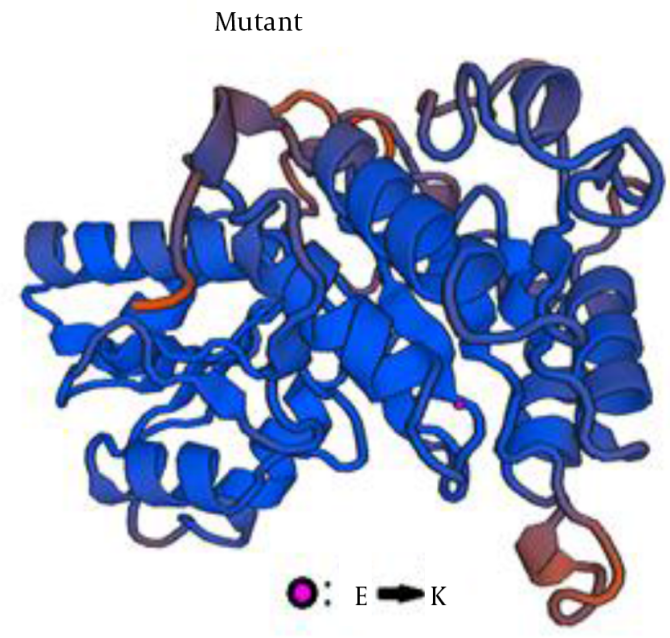

$\mathrm{A}$, the predicted 3D structure of normal protein product of the BCKDHB gene (wild-type E1 $\beta$ protein); B, the E330K mutant E1 $\beta$ protein structure. (Pictures prepared by Swiss model software).

could confirm definitely the Pathogenicity of the detected change in our patient.

Finally, identification of the novel mutation shed some light on the molecular pathology of MSUD in Iranian subjects. In the meantime, the detection of the novel mutation in the Iranian patient would facilitate prenatal identification in her at-risk family.

\section{Acknowledgments}

The authors wish to thank the Narges genetic laboratory staff and all members of the MSUD family for their cooperation. This work was supported by a grant from research council of University of Zanjan (code 34355). We also thank kindly M. Zamani for editing the manuscript.

\section{Footnotes}

Authors' Contribution: Esmat Safdarian made laboratory procedures. Hamid Galehdari designed the project and primers. Vahab Jafarian was the main supervisor. Mohammad Shafee performed bioinformatics steps. Gholamreza Shariati diagnosed clinically the disease. Mohammad Hamid designed the manuscript and bioinformatics. Alihossein Saberi designed the manuscript and bioinformatics.

Conflict of Interests: The authors declare no conflict of interest.

Funding/Support: University of Zanjan. 


\section{References}

1. Chuang JL, Wynn RM, Moss CC, Song JL, Li J, Awad N, et al. Structural and biochemical basis for novel mutations in homozygous Israeli maple syrup urine disease patients: a proposed mechanism for the thiamin-responsive phenotype. J Biol Chem. 2004;279(17):17792-800. doi: 10.1074/jbc.M313879200. [PubMed: 14742428].

2. Edelmann L, Wasserstein MP, Kornreich R, Sansaricq C, Snyderman SE, Diaz GA. Maple syrup urine disease: identification and carrierfrequency determination of a novel founder mutation in the Ashkenazi Jewish population. Am J Hum Genet. 2001;69(4):863-8. doi: 10.1086/323677. [PubMed: 11509994].

3. Nellis MM, Kasinski A, Carlson M, Allen R, Schaefer AM, Schwartz EM, et al. Relationship of causative genetic mutations in maple syrup urine disease with their clinical expression. Mol Genet Metab. 2003;80(1 2):189-95. [PubMed:14567968].

4. Chuang DT, Chuang JL, Wynn RM. Lessons from genetic disorders of branched-chain amino acid metabolism. J Nutr. 2006;136(1 Suppl):243S-9S. [PubMed: 16365091].

5. Quintana E, Pineda M, Font A, Vilaseca MA, Tort F, Ribes A, et al. Dihydrolipoamide dehydrogenase (DLD) deficiency in a Spanish patient with myopathic presentation due to a new mutation in the interface domain. J Inherit Metab Dis. 2010;33 Suppl 3:S315-9. doi: 10.1007/s10545-010-9169-4. [PubMed: 20652410].

6. Quental S, Gusmao A, Rodriguez-Pombo P, Ugarte M, Vilarinho L, Amorim A, et al. Revisiting MSUD in Portuguese Gypsies: evidence for a founder mutation and for a mutational hotspot within the BCK-
DHA gene. Ann Hum Genet. 2009;73(Pt 3):298-303. doi: 10.1111/j.14691809.2009.00518.x. [PubMed: 19456321].

7. Morton DH, Strauss KA, Robinson DL, Puffenberger EG, Kelley RI. Diagnosis and treatment of maple syrup disease: a study of 36 patients. Pediatrics. 2002;109(6):999-1008. [PubMed:12042535].

8. Kalendar R, Lee D, Schulman AH. Java web tools for PCR, in silico PCR, and oligonucleotide assembly and analysis. Genomics. 2011;98(2):13744. doi: 10.1016/j.ygeno.2011.04.009. [PubMed: 21569836].

9. Kalendar R, Lee D, Schulman AH. FastPCR software for PCR, in silico PCR, and oligonucleotide assembly and analysis. Methods $\mathrm{Mol}$ Biol. 2014;1116:271-302. doi: 10.1007/978-1-62703-764-8_18. [PubMed: 24395370].

10. Adzhubei IA, Schmidt S, Peshkin L, Ramensky VE, Gerasimova A, Bork $\mathrm{P}$, et al. A method and server for predicting damaging missense mutations. Nat Methods. 2010;7(4):248-9. doi: 10.1038/nmeth0410-248. [PubMed: 20354512].

11. Kumar P, Henikoff S, Ng PC. Predicting the effects of coding nonsynonymous variants on protein function using the SIFT algorithm. Nat Protoc. 2009;4(7):1073-81. doi: 10.1038/nprot.2009.86. [PubMed: 19561590].

12. Schwarz JM, Rodelsperger C, Schuelke M, Seelow D. MutationTaster evaluates disease-causing potential of sequence alterations. Nat Methods. 2010;7(8):575-6. doi: 10.1038/nmeth0810-575. [PubMed: 20676075].

13. Flaschker N, Feyen O, Fend S, Simon E, Schadewaldt P, Wendel U. Description of the mutations in 15 subjects with variant forms of maple syrup urine disease. J Inherit Metab Dis. 2007;30(6):903-9. doi: 10.1007/s10545-007-0579-x. [PubMed: 17922217]. 